Kansas State University Libraries

New Prairie Press

\title{
DISTRIBUTION OF BOLL NUMBER AND LINT YIELD BY TIME AND POSITION IN UPLAND COTTON CULTIVATORS
}

Jixiang Wu

Johnie N. Jenkins

Jack C. McCarty Jr.

Follow this and additional works at: https://newprairiepress.org/agstatconference

Part of the Agriculture Commons, and the Applied Statistics Commons

\section{(c) (1) $\Theta(9$}

This work is licensed under a Creative Commons Attribution-Noncommercial-No Derivative Works 4.0 License.

\section{Recommended Citation}

Wu, Jixiang; Jenkins, Johnie N.; and McCarty, Jack C. Jr. (2004). "DISTRIBUTION OF BOLL NUMBER AND LINT YIELD BY TIME AND POSITION IN UPLAND COTTON CULTIVATORS," Conference on Applied Statistics in Agriculture. https://doi.org/10.4148/2475-7772.1168

This is brought to you for free and open access by the Conferences at New Prairie Press. It has been accepted for inclusion in Conference on Applied Statistics in Agriculture by an authorized administrator of New Prairie Press. For more information, please contact cads@k-state.edu. 


\title{
Distribution of Boll Number and Lint Yield by Time and Position in Upland Cotton Cultivars
}

\author{
Jixiang $\mathrm{Wu}^{*}$, Johnie N. Jenkins, and Jack C. McCarty, Jr. \\ J. Wu, Department of Plant and Soil Sciences, Mississippi State University, Mississippi State, \\ MS 39762; J. N. Jenkins and J. C. McCarty, Jr. Crop Science Research Laboratory, USDA-ARS, \\ Mississippi State, MS 39762.
}

\begin{abstract}
The time period and position which make the major contribution to total yield and to its variation is important for the field management and breeding for upland cotton, Gossypium hirsutum, L. Two-year end-of-season plant mapping data from 11 upland cotton cultivars were analyzed by position and by week. The data showed that the first position in the second and third weeks made the largest contribution to the total boll number and lint yield. The eleven cultivars differed with respect to the earliness but they had similar lint yield at harvest. The early season cultivars produce more yield and more bolls than late season cultivars in the first week of blooming, while the late season cultivars produce more yield and more bolls in the fourth week and later. The genotypic variance was the largest in week 5 and later for both lint yield and boll number. Thus, these results suggested that appropriate field management is required to maintain high yield in weeks 2 and 3 and to obtain maximum yield at late season, especially for late season cultivars. Breeders could be able to cross two cultivars which differ in earliness to obtain high yielding lines.
\end{abstract}

Key words: upland cotton; position; yield distribution; boll distribution.

\section{Introduction}

The initiation and development of a square (bud) to an open boll in a cotton plant is sitedependent and time-dependent. The potential fruiting branches could cover main stem nodes 5 through 23 and the blooming time from late June to the middle of August in Mississippi. Such a long growing season may complicate field management and breeding techniques to obtain the maximum of number of open bolls and yield at harvest.

*Contact author (jw7@ra.msstate.edu). Contribution of the USDA-ARS in cooperation with the Mississippi Agric. and Forestry Exp. Stn. 
Counting and tagging the blooming date at each fruiting site has been used to investigate the earliness and boll distribution for a cotton genotype (Zhu et al., 1993; Zhu, 1995; Chen et al., 1999, 2000; Ye and Zhu, 2000, 2001a,b). Zhu et al. (1993) found that the first and second positions accounted for $61 \%$ and $73 \%$ of total blooms and bolls, respectively, while the other positions contributed $39 \%$ and $27 \%$, respectively. Dominance effects were more important than additive effects for the cumulative boll number and seed cotton yield in early season, while additive effects became more important late in the season (Zhu et al., 1993, Zhu, 1995; Chen et al., 1999; Ye and Zhu, 2000). Chen et al. (1999, 2000) found that some $\mathrm{F}_{1}$ hybrids had strong heterosis in early season and some others had strong heterosis in late season for seed cotton yield. Tagging the date for each bloom on a number of plants at each fruiting site is very timeconsuming in practice. The vertical flowering interval (VFI) and horizontal flowering interval (HFI) are temperature-dependent as well as dependent upon the number of maturing fruit on the plant. Manuney (1986) cited several studies that showed a VFI range of 2.2 to 4.0 days and a HFI range of 5.8 to 8.5 days (Hesketh et al., 1972; McClelland and Neely, 1931; McNamara et al., 1940). Ye and Zhu (2001a) reported that the mean VFI and HVI were 2.3 and 5.7 days, respectively. Cotton cultivars in Mississippi generally have about 3- and 6-day VFI and HFI. Thus, box-mapping (or end-of-season plant mapping) was used to investigate the earliness of cotton cultivars and distribution of cotton yield and boll number (Jenkins et al., 1990a,b; McCarty et al., 1994; Jenkins and McCarty, 1995; Shoemaker, 2000). These studies showed that bolls from first position contribute $66 \sim 75 \%$, and bolls from second position $18 \sim 21 \%$, to total yield of modern cultivars.

Based on average VFI and HFI values, we converted the two-year end-of-season mapping data (Jenkins and McCarty, 1995) to lint yield and boll number by position and by week. This conversion may provide a better insight to cultivar earliness, distribution patterns of boll number and yield at different times and positions. The genetic variations for boll number and lint yield by time and position were estimated. The main purposes of this study were: (1) to determine the contribution that time period and position make the largest contribution to total boll number and lint yield and (2) to determine the contribution that time period and position make the largest contribution to the variance of total boll number and lint yield. Thus, these results may provide important information for cotton field management and cotton breeding programs to obtain the maximum yield and benefit.

\section{Materials and Methods}

\subsection{Materials}

Eleven upland cotton commercial cultivars, Chembred 1135 (CB1135), Chembred 219 (CB219), Chembred 232 (CB232), Chembred 407 (CB407), DES 119, Deltapine 51 (DP51), Deltapine 5415 (DP5415), Deltapine 5690 (DP5690), Deltapine Acala 90 (DP90), LA 850082FN (LA8582), and Stoneville 69132 (ST69132), were used in this study (Jenkins and McCarty, 1995). These cotton lines were planted in two row plots, spaced 38 inches apart and were 30 and 43 feet in length in 1990 and 1991, respectively. The experimental design was a randomized complete block design with six replications on a Marietta sandy clay loam (fine-loamy, siliceous, thermic Fluvaquentic Eutrochrept) soil. Planting dates were April 25, 1990 and May 21, 1991. 
The delayed planting in 1991 was because of the very wet spring. Normal field practices were followed during the growing season.

At harvest, the open bolls from the plants in a $10-\mathrm{ft}$ section of row in each plot were collected, counted, and weighed by fruiting site following the technique of Jenkins et al. (1990a). The procedure for the data collection was detailed by Jenkins and McCarty (1995). A sample containing 50 bolls was collected prior to machine picking for each plot. Each sample was ginned to determine the boll size and lint percentage. The mean lint percentage over six replications was used to convert each replication of a genotype into lint cotton. The machineharvest weights were converted to weight of lint per acre and this was distributed across fruiting sites according to the percentage distribution from the mapped plants from the 10-ft mapped sample for each plot. The number of bolls and weight of lint by each fruiting site (or by node and position) were summed by position for each plot (Jenkins and McCarty, 1995). The number of bolls and weight of lint were converted to the respective values by week according VFI of 3 days and HFI of 6 days.

\subsection{Genetic Models and Statistical Methods}

A genotype with genotype $\times$ environment $(G \times E)$ interaction model was used for the data analysis. The mixed linear model for genotype $i$ in block $j$ within environment $h$ was as follows: $y_{h i j}=\mu+E_{h}+G_{i}+G E_{h i}+B_{j(h)}+e_{h i j}$

where, $\mu$ is the fixed population (or grand) mean; $E_{h}$ is the random environmental effect; $G_{i}$ is the random genotypic effect; $G E_{h i}$ is the random $G \times E$ interaction effect; $B_{j(h)}$ is the random block effect; and $e_{h i j}$ is the random error.

Variance components were estimated by minimum norm quadratic unbiased estimation (MINQUE), in which all prior values were set to 1.0 (Zhu, 1989). The phenotypic variance $\left(V_{\mathrm{P}}\right)$ was defined as, $V_{p}=V_{G}+V_{G E}+V_{e}$ where, $V_{G}=\sigma_{G}^{2}$ variance for genotypic effects, $V_{G E}=\sigma_{G E}^{2}$ variance for $G \times E$ interaction effects, and $V_{e}=\sigma_{e}^{2}$ variance for random errors. Resampling using the jackknifing procedure was applied to calculate the standard error (SE) for each parameter by successive removal of one block within each environment (Miller, 1974). The t-test was used to test the significance of each parameter (degrees of freedom $=11$ ). All data were analyzed using a program written in $\mathrm{C}++$.

\section{Results and Discussion}

\subsection{Boll Number and Lint Yield by Position}

The first position accounted for $69 \%$ of total bolls and $74 \%$ of total yield, second position values were $20 \%$ and $17 \%$, and the third position less than $10 \%$. Genotypic variance for total lint yield was not significant; however, genotypic variance was significant for total boll number, indicating that these cultivars had similar lint yield with different numbers of bolls at harvest. Genotypic variance was significant for lint yield at the third position while not significant at positions 1 and 2. Genotypic variance was significant for boll number on position 1, 2, and 3, while the first position had the largest genotypic variance. The results indicated that position 1 
made the majority of contribution to total boll number and lint yield; however, the use of total yield at the first position to distinguish the earliness of a cultivar might not be appropriate. The possible reason is that early season cultivars had more yield at position 1 in the early season while late season cultivars had more yield at position 1 in the late season when they had the same yield.

\subsection{Proportions of Boll Number and Lint Yield by Week}

The proportions of boll number and lint yield by week to total boll number and total lint yield are summarized in Table 1. On average, the first week contributed $14 \%$ and $17 \%$ of total boll number and total lint yield, respectively (Table 1). Second and third weeks made the majority of bolls and lint yield, $43 \%$ and $46 \%$, respectively, indicating that the growing season at weeks 2 and 3 after first blooming was the most important time for producing open bolls and cotton yield. Weeks 4 and 5 contributed about 17\% to total bolls and $15.5 \%$ to lint yield.

The earliness of cotton cultivars based on the proportions of boll number and lint yield by week could be seen. DES 119 and ST 69132 had a larger contribution in the first week but less in week 5 to the total bolls and lint yield, indicating that these two cultivars are earlier than the other nine cultivars (Table 1). On the other hand, DP 90 and DP 5690 were two cultivars that had a smaller contribution in the first week but greater in week 5 to the total bolls and lint yield, indicating that these two cultivars are later than the other nine cultivars.

Within each growing period (week), distributions of boll number and lint yield among cultivars varied greatly (Tables 2 and 3). On average, the first position accounted for $94 \%$ and $96 \%$ of total bolls and lint yield in the first week, respectively; while the second position for only $6 \%$ and $4 \%$ of total bolls and lint yield in the first week, respectively (Tables 2 and 3). The first, second, and third positions accounted for $72 \%, 26 \%$, and $3 \%$ to the total bolls during weeks 2 and 3 , respectively; $77 \%, 22 \%$, and $2 \%$ to total lint yield in week 2 plus 3 , respectively. The first, second, and third positions accounted for $70 \%, 24 \%$, and $6 \%$ to the total bolls in week 4 or 5 , respectively; for $75 \%, 21 \%$, and $2 \%$ to total lint yield in week 4 or 5 , respectively.

\subsection{Genetic Variances of Boll Number and Lint Yield by Position during Growing Season}

The proportion of boll number and lint yield could be indicative of the importance of a position during a specific growing period to the total bolls and lint yield (Tables 1, 2, 3), but it may not specify which position makes the differences in total bolls and lint yield. Thus, the variance components of boll number and lint yield in four growing time periods and by position within each of four time periods were estimated and summarized in Tables 4 and 5.

\subsubsection{Boll Number}

The genetic variance components of boll number for weeks 1, 2 and 3, and 4 were not significantly different, but they were significantly lower than that in week 5 (Table 4), indicating that the week 5 (or late season) could make a greater difference in total boll. In week 1, each variance component (genetic, $\mathrm{G} \times \mathrm{E}$ interaction, or residual component) at the first position was greater than each corresponding one at the second position. In weeks 2 and 3, genotypic variances of boll number at position 2 were significantly greater than that at positions 1 and 3 . $\mathrm{G} \times \mathrm{E}$ interaction variance at position 1 was greater than that at position 2 , but 2 was not significantly greater than that at position 3 . Residual variance at position 1 was greater than that 
at position 2 , which was significantly greater than that at position 3 . In week 4 , genetic and $\mathrm{G} \times \mathrm{E}$ interaction variances at position 1 were greater than those at 2, which were significantly greater than those at position 3; residual variance at position 1 was greater than that at position 2, which was not significantly greater than that at 3 . In week 5, variances of genotype and residual at position 1 were greater than those at position 2, which were significantly greater than those at position 3; $\mathrm{G} \times \mathrm{E}$ interaction variances at positions 1 and 2 was not different, but significantly greater than that at position 3. In summary, the genetic variation at position 1 was greater that that at position 2 during each growing period except week 2 plus 3 , and the genetic variation at position 2 was generally greater than that at position 3 (Table 4). The genetic variance components of number of bolls for weeks 1, 2 and 3, and 4 were not significantly different, but were significantly lower than that in week 5 , indicating that the first position in week 5 made the majority of difference in total boll number.

\subsubsection{Lint Yield}

The genetic variance components of lint yield (all positions) for weeks 1, 2 and 3, and 4 were not significantly different, but were significantly lower than that in week 5 (Table 5), indicating that week 5 (or late season) could make a greater difference in total lint yield. In week 1, each variance component (genetic, $\mathrm{G} \times \mathrm{E}$ interaction, or residual component) at the first position was greater than each corresponding one at the second position. In weeks 2 and 3 , genetic variances of lint yield at positions 1 and 2 were not significantly different, but were greater than that at position 3. Variances of $\mathrm{G} \times \mathrm{E}$ interaction and residual at position 1 was greater than that at position 2 , which were significantly greater than that at position 3 . In week 4, genetic and residual variances at position 1 were greater than those at position 2 , which were significantly greater than at position 3; $\mathrm{G} \times \mathrm{E}$ interaction variance of lint yield at position 1 was significant (from zero), while no $\mathrm{G} \times \mathrm{E}$ interaction effects of lint yield were detected at positions 2 and 3. In week 5, variances of genotype and residual at position 1 were greater than those at position 2 , which were significantly greater than those at position $3 ; \mathrm{G} \times \mathrm{E}$ interaction variances at positions 1 and 2 were not different, but significantly greater than that at position 3 . In summary, the genetic variation in lint yield at position 1 was greater that at 2 in each growing period except week 2 plus 3, and the genetic variation at 2 was generally greater than that at position 3 (Table 5). The genetic variance components for lint yield at first position in weeks 1, 2 and 3 , and 4 were not significantly different, but they were significantly lower than that in week 5 , indicating that the first position in week 5 contributed the majority of variance to total lint yield. The results in Table 5 were in agreement with those in Table 4.

\section{Summary}

The 11 upland cotton cultivars differed with respect to earliness but they had similar lint yield. This suggested that both early and late season cultivars could yield similar by via different growth patterns. The early season cultivars produce more yield and bolls than late season ones in the first week of blooming, while the late season cultivars produce more yield and bolls in the fourth week and later. The first position made the major contribution to total lint yield and boll number, while there was no significant genetic difference among 11 cultivars for lint yield at first position. The second and third weeks of blooming accounted for the major contribution to total lint yield and boll number. The largest genotypic variance was in week 5 and later for lint yield 
and boll number. Thus, these results suggested that appropriate field management is required to obtain high yield in weeks 2 and 3 and to obtain maximum yield at late season, especially for late season cultivars. Genetic variances suggested that breeders should be able to cross cultivars which differ in earliness to develop high yielding lines.

\section{References}

- Chen, Q., J. Zhu, and J. Wu. 1999. Developmental genetic analysis of boll number and seed cotton yield per plant at different fruiting stages in upland cotton (Gossypium hirsutum L.). Journal of Zhejiang Agricultural University 25(2): 155-160

- Chen, Q., Zhu, J., and Wu, J. 2000. Genetic study on seed cotton yield at different boll setting stages and fruiting sites in upland cotton. Scientia Agricultura Sinica 33(4): 97-99.

- Hesketh, J. D., D. N. baker, and W. G. Duncan. 1972. Simulation of growth and yield in cotton: II. Environmental control of morphogenesis. Crop Sci. 12:436-439.

- Jenkins, J. N., and J. C. McCarty, Jr. 1995. End of season plant maps. Mississippi Agricultural \& Forestry Experiment Station. Bull. 1024. Mississippi State, MS

- Jenkins, J. N., J. C. McCarty, Jr. and W. L. Parrot. 1990a. Effectiveness of fruiting sites in cotton: yield. Crop Sci. 30:365-369.

- Jenkins, J.N., J.C. McCarty, Jr. and W. L. Parrot. 1990b. Fruiting efficiency in cotton: Boll size and boll set percentage. Crop Sci. 30:857-860.

- Mauney, J.R. 1986. Vegetative growth and development of fruiting sites. In Cotton Physiology, J. C. Mauney and J. M. Stewart (eds). The Cotton Foundation, Memphis, TN.

- McClelland, C. K., and J. W. Neely. 1931. The order, rate and regularity of blooming in the cotton plant. J. Agric. Res. 42:751-764.

- McNamara, H. C., D. R. Hooten, and D. D. Porter. 1940. Differential growth rates in cotton varieties and their response to seasonal condition at Greenville, Texas. USDA Tech Bull. 710.

- Miller, R. G. 1974. The jackknife: a review. Biometrika 61: 1-15.

- McCarty, W., J. N. Jenkins, and J. C. McCarty. 1994. Using plant mapping to evaluate cotton at harvest. Publication 1975, Coop. Ext. Serv., Mississippi State University.

- Shoemaker, D. 2000. Genetic analysis of agronomic traits of selected American and Australian cotton genotypes and their $\mathrm{F}_{2}$ hybrids. Ph.D. Diss., Mississippi State Univ., Mississippi State, MS.

- Ye, Z., and J. Zhu. 2000. Genetic analysis of flowering and boll setting in upland cotton (Gossypium hirsutum L.) III. Genetic behavior at different developing stages Acta Genetica Sinica 27(9): 800-809. 
- Ye, Z., and J. Zhu. 2001a. Genetic analysis of flowering and boll setting in upland cotton (Gossypium hirsutum L.) II. The genetic behavior of different fruiting sites. Acta Agronomica Sinica 27(2): 243-252.

- Ye, Z., and J. Zhu. 2001b. Genetic analysis of flowering and boll setting in upland cotton (Gossypium hirsutum L.): Flowering behavior and its influencing factors. Journal of Zhejiang University (Agriculture \& Life Sciences) 27(1): 62-68.

- Zhu, J. 1989. Estimation of genetic variance components in the general mixed model. Ph.D. Dissertation, North Carolina State University, Raleigh, U.S.A.

- Zhu, J. 1995. Analysis of conditional effects and variance components in developmental genetics. Genetics 141(4): 1633-1699.

- Zhu, J., D. Ji, and F. Xu. 1993. Genetic analysis for flowering and fruiting of different sites on cotton plant. Acta Gossypii Sinica. 5(1): 25-32. 
Table 1. Distributions of boll number and lint yield by week expressed as proportions to the total values.

\begin{tabular}{|c|c|c|c|c|}
\hline & \multicolumn{4}{|c|}{ Boll number } \\
\hline & $\mathrm{W} 1$ & W23 & W4 & W5 \\
\hline CB1135 & 0.17 & 0.47 & 0.15 & 0.15 \\
\hline CB219 & 0.16 & 0.48 & 0.15 & 0.15 \\
\hline CB232 & 0.16 & 0.43 & 0.16 & 0.16 \\
\hline CB407 & 0.12 & 0.40 & 0.18 & 0.21 \\
\hline DES119 & 0.20 & 0.49 & 0.13 & 0.11 \\
\hline DPL51 & 0.14 & 0.39 & 0.16 & 0.22 \\
\hline DPL5415 & 0.14 & 0.41 & 0.15 & 0.20 \\
\hline DPL5690 & 0.11 & 0.37 & 0.18 & 0.26 \\
\hline DPL90 & 0.09 & 0.38 & 0.17 & 0.26 \\
\hline LA850082 & 0.12 & 0.44 & 0.16 & 0.19 \\
\hline ST69132 & 0.20 & 0.45 & 0.15 & 0.12 \\
\hline \multirow[t]{3}{*}{ Mean } & 0.14 & 0.43 & 0.16 & 0.18 \\
\hline & \multicolumn{4}{|c|}{ Lint yield } \\
\hline & $\mathrm{W} 1$ & W23 & W4 & W5 \\
\hline CB1135 & 0.19 & 0.50 & 0.14 & 0.12 \\
\hline CB219 & 0.19 & 0.51 & 0.13 & 0.11 \\
\hline CB232 & 0.19 & 0.47 & 0.15 & 0.13 \\
\hline CB407 & 0.14 & 0.43 & 0.18 & 0.17 \\
\hline DES119 & 0.23 & 0.51 & 0.12 & 0.08 \\
\hline DPL51 & 0.17 & 0.41 & 0.16 & 0.19 \\
\hline DPL5415 & 0.15 & 0.45 & 0.15 & 0.17 \\
\hline DPL5690 & 0.13 & 0.41 & 0.17 & 0.22 \\
\hline DPL90 & 0.10 & 0.42 & 0.18 & 0.22 \\
\hline LA850082 & 0.14 & 0.48 & 0.16 & 0.15 \\
\hline ST69132 & 0.24 & 0.49 & 0.13 & 0.08 \\
\hline Mean & 0.17 & 0.46 & 0.16 & 0.15 \\
\hline
\end{tabular}

W1, W23, W4, and W5 refer as week 1, 2 and 3, 4, and 5 (and above). 
Table 2. Distributions of boll number by week and position.

\begin{tabular}{|c|c|c|c|c|c|c|c|}
\hline & \multicolumn{4}{|c|}{ Actual value $^{+}$} & \multicolumn{3}{|c|}{ Proportion $^{\neq}$} \\
\hline & $\mathrm{W} 1-\mathrm{P} 1^{\Delta}$ & W1-P2 & W1-P3 & $\mathrm{W} 1^{*}$ & W1-P1 & W1-P2 & W1-P3 \\
\hline CB1135 & 41.1 & 2.6 & -- & 43.7 & 0.94 & 0.06 & -- \\
\hline CB219 & 37.5 & 2.9 & -- & 40.5 & 0.93 & 0.07 & -- \\
\hline CB232 & 42.4 & 2.7 & -- & 45.1 & 0.94 & 0.06 & -- \\
\hline CB407 & 33.7 & 1.4 & -- & 35.1 & 0.96 & 0.04 & -- \\
\hline DES119 & 49.5 & 4.0 & -- & 53.5 & 0.93 & 0.07 & -- \\
\hline DPL51 & 41.1 & 3.6 & -- & 44.7 & 0.92 & 0.08 & -- \\
\hline DPL5415 & 40.9 & 2.1 & -- & 43.0 & 0.95 & 0.05 & -- \\
\hline DPL5690 & 32.6 & 0.5 & -- & 33.1 & 0.99 & 0.01 & -- \\
\hline DPL90 & 24.9 & 0.9 & -- & 25.8 & 0.97 & 0.03 & -- \\
\hline LA850082 & 31.4 & 2.5 & -- & 33.9 & 0.93 & 0.07 & -- \\
\hline ST69132 & 43.6 & 4.5 & -- & 48.0 & 0.91 & 0.09 & -- \\
\hline \multirow[t]{2}{*}{ Mean } & 38.06 & 2.52 & -- & 40.58 & 0.94 & 0.06 & -- \\
\hline & W23-P1 & W23-P2 & W23-P3 & W23 & W23-P1 & W23-P2 & W23-P3 \\
\hline CB1135 & 89.7 & 29.3 & 3.4 & 122.4 & 0.73 & 0.24 & 0.03 \\
\hline CB219 & 86.0 & 33.7 & 2.7 & 122.5 & 0.70 & 0.28 & 0.02 \\
\hline CB232 & 87.5 & 29.6 & 3.2 & 120.4 & 0.73 & 0.25 & 0.03 \\
\hline CB407 & 81.9 & 28.2 & 2.5 & 112.5 & 0.73 & 0.25 & 0.02 \\
\hline DES119 & 89.4 & 37.9 & 2.5 & 129.8 & 0.69 & 0.29 & 0.02 \\
\hline DPL51 & 85.6 & 31.9 & 4.2 & 121.7 & 0.70 & 0.26 & 0.03 \\
\hline DPL5415 & 93.5 & 32.9 & 2.0 & 128.4 & 0.73 & 0.26 & 0.02 \\
\hline DPL5690 & 87.2 & 22.2 & 1.7 & 111.1 & 0.78 & 0.20 & 0.02 \\
\hline DPL90 & 80.3 & 24.6 & 2.9 & 107.7 & 0.75 & 0.23 & 0.03 \\
\hline LA850082 & 82.2 & 37.1 & 4.8 & 124.0 & 0.66 & 0.30 & 0.04 \\
\hline ST69132 & 75.7 & 28.9 & 5.0 & 109.6 & 0.69 & 0.26 & 0.05 \\
\hline \multirow[t]{2}{*}{ Mean } & 85.36 & 30.57 & 3.17 & 119.10 & 0.72 & 0.26 & 0.03 \\
\hline & W4-P1 & W4-P2 & W4-P3 & W4 & W4-P1 & W4-P2 & W4-P3 \\
\hline CB1135 & 29.6 & 8.9 & 1.9 & 40.5 & 0.73 & 0.22 & 0.05 \\
\hline CB219 & 26.1 & 9.7 & 2.3 & 38.0 & 0.69 & 0.25 & 0.06 \\
\hline CB232 & 31.4 & 10.1 & 2.4 & 43.9 & 0.72 & 0.23 & 0.06 \\
\hline CB407 & 36.1 & 11.7 & 2.3 & 50.1 & 0.72 & 0.23 & 0.05 \\
\hline DES119 & 26.2 & 7.6 & 1.8 & 35.6 & 0.74 & 0.21 & 0.05 \\
\hline DPL51 & 35.3 & 12.1 & 2.9 & 50.2 & 0.70 & 0.24 & 0.06 \\
\hline DPL5415 & 33.1 & 12.6 & 1.7 & 47.5 & 0.70 & 0.27 & 0.04 \\
\hline DPL5690 & 37.6 & 12.4 & 2.0 & 51.9 & 0.72 & 0.24 & 0.04 \\
\hline DPL90 & 33.2 & 13.5 & 2.3 & 49.0 & 0.68 & 0.27 & 0.05 \\
\hline LA850082 & 31.7 & 12.0 & 2.5 & 46.3 & 0.69 & 0.26 & 0.05 \\
\hline ST69132 & 24.6 & 9.2 & 3.7 & 37.5 & 0.66 & 0.25 & 0.10 \\
\hline Mean & 31.35 & 10.89 & 2.35 & 44.59 & 0.70 & 0.24 & 0.06 \\
\hline
\end{tabular}


Table 2. (continued)

\begin{tabular}{lccccccc}
\hline & W5-P1 & W5-P2 & W5-P3 & W5 & W5-P1 & W5-P2 & W5-P3 \\
\cline { 2 - 8 } CB1135 & 27.9 & 9.6 & 2.1 & 39.6 & 0.71 & 0.24 & 0.05 \\
CB219 & 27.4 & 8.3 & 2.3 & 38.0 & 0.72 & 0.22 & 0.06 \\
CB232 & 31.1 & 11.8 & 3.2 & 46.0 & 0.68 & 0.26 & 0.07 \\
CB407 & 42.1 & 14.7 & 2.6 & 59.4 & 0.71 & 0.25 & 0.04 \\
DES119 & 20.0 & 7.4 & 1.9 & 29.3 & 0.68 & 0.25 & 0.07 \\
DPL51 & 47.0 & 17.8 & 5.1 & 69.9 & 0.67 & 0.26 & 0.07 \\
DPL5415 & 45.1 & 13.9 & 2.6 & 61.6 & 0.73 & 0.23 & 0.04 \\
DPL5690 & 55.0 & 18.3 & 3.0 & 76.3 & 0.72 & 0.24 & 0.04 \\
DPL90 & 48.7 & 18.7 & 4.4 & 71.8 & 0.68 & 0.26 & 0.06 \\
LA850082 & 41.1 & 10.1 & 2.4 & 53.6 & 0.77 & 0.19 & 0.04 \\
ST69132 & 19.2 & 6.9 & 3.2 & 29.4 & 0.65 & 0.24 & 0.11 \\
Mean & 36.78 & 12.50 & 2.98 & 52.26 & 0.70 & 0.24 & 0.06 \\
\hline
\end{tabular}

†: Averaged boll number in 10 -ft section over two years;

$\Delta$ : Wi-Pj refers to week $\mathrm{i}$ and position $\mathrm{j}$.

s: W1, W23, W4, and W5 refer to averaged boll number in 10-ft section over two years in for week 1, 2 and 3, 4, and 5 (and above);

f: Proportion to total boll number by position within a specific time period, for example: W1-P1 refers to the proportion value of position 1 to total boll number in the first week. 
Table 3. Distributions of lint yield by week and position $(\mathrm{kg} / \mathrm{ha})$

\begin{tabular}{|c|c|c|c|c|c|c|c|}
\hline & \multicolumn{4}{|c|}{ Actual value $^{+}$} & \multicolumn{3}{|c|}{ Proportion $^{\neq}$} \\
\hline & $\mathrm{W}^{\mathrm{W} 1-\mathrm{P} 1^{\Delta}}$ & W1-P2 & W1-P3 & $\overline{\mathrm{W} 1} 1^{*}$ & W1-P1 & W1-P2 & W1-P3 \\
\hline CB1135 & 329.31 & 14.46 & -- & 343.77 & 0.96 & 0.04 & -- \\
\hline CB219 & 314.31 & 19.35 & -- & 333.67 & 0.94 & 0.06 & -- \\
\hline CB232 & 314.99 & 14.51 & -- & 329.50 & 0.96 & 0.04 & $\ldots$ \\
\hline CB407 & 255.13 & 10.30 & -- & 265.43 & 0.96 & 0.04 & -- \\
\hline DES119 & 388.60 & 26.18 & -- & 414.78 & 0.94 & 0.06 & -- \\
\hline DPL51 & 277.58 & 18.11 & -- & 295.69 & 0.94 & 0.06 & -- \\
\hline DPL5415 & 260.76 & 9.23 & -- & 270.00 & 0.97 & 0.03 & -- \\
\hline DPL5690 & 247.72 & 2.68 & -- & 250.40 & 0.99 & 0.01 & -- \\
\hline DPL90 & 189.82 & 4.59 & -- & 194.40 & 0.98 & 0.02 & -- \\
\hline LA850082 & 227.10 & 12.67 & -- & 239.77 & 0.95 & 0.05 & -- \\
\hline ST69132 & 373.02 & 33.81 & -- & 406.83 & 0.92 & 0.08 & -- \\
\hline \multirow[t]{2}{*}{ Mean } & 288.94 & 15.08 & -- & 304.02 & 0.96 & 0.04 & -- \\
\hline & W23-P1 & W23-P2 & W23-P3 & W23 & W23-P1 & W23-P2 & W23-P3 \\
\hline CB1135 & 691.80 & 180.69 & 16.10 & 888.59 & 0.78 & 0.20 & 0.02 \\
\hline CB219 & & 214.54 & 11.93 & 909.94 & 0.75 & 0.24 & 0.01 \\
\hline CB232 & 639.91 & 162.85 & 13.32 & 816.08 & 0.78 & 0.20 & 0.02 \\
\hline CB407 & 628.63 & 170.83 & 10.45 & 809.91 & 0.78 & 0.21 & 0.01 \\
\hline DES119 & 674.86 & 236.14 & 10.14 & 921.14 & 0.73 & 0.26 & 0.01 \\
\hline DPL51 & 7.90 & 161.64 & 17.60 & 727.14 & 0.75 & 0.22 & 0.02 \\
\hline DPL5415 & & 172.80 & 8.24 & 811.09 & 0.78 & 0.21 & 0.01 \\
\hline DPL5690 & 651.35 & 133.03 & 7.03 & 791.41 & 0.82 & 0.17 & 0.01 \\
\hline DPL90 & 617.99 & 147.00 & 13.45 & 778.44 & 0.79 & 0.19 & 0.02 \\
\hline LA850082 & 593.82 & 209.49 & 22.39 & 825.71 & 0.72 & 0.25 & 0.03 \\
\hline ST69132 & 605.08 & 179.91 & 23.29 & 808.29 & 0.75 & 0.22 & 0.03 \\
\hline \multirow[t]{2}{*}{ Mean } & 633.17 & 178.99 & 13.99 & 826.16 & 0.77 & 0.22 & 0.02 \\
\hline & W4-P1 & W4-P2 & W4-P3 & W4 & W4-P1 & W4-P2 & W4-P3 \\
\hline CB1135 & 193.33 & 52.15 & 9.17 & 254.65 & 0.76 & 0.20 & 0.04 \\
\hline CB219 & 177.38 & 50.52 & 10.07 & 237.96 & 0.75 & 0.21 & 0.04 \\
\hline CB232 & 203.90 & 49.26 & 9.86 & 263.03 & 0.78 & 0.19 & 0.04 \\
\hline CB407 & 258.07 & 65.46 & 9.64 & 333.17 & 0.77 & 0.20 & 0.03 \\
\hline DES119 & 163.39 & 41.05 & 9.14 & 213.58 & 0.77 & 0.19 & 0.04 \\
\hline DPL51 & 214.29 & 57.83 & 11.74 & 283.85 & 0.75 & 0.20 & 0.04 \\
\hline DPL5415 & 204.89 & 62.93 & 7.33 & 275.16 & 0.74 & 0.23 & 0.03 \\
\hline DPL5690 & 248.47 & 68.66 & 8.25 & 325.38 & 0.76 & 0.21 & 0.03 \\
\hline DPL90 & 242.75 & 81.01 & 10.55 & 334.31 & 0.73 & 0.24 & 0.03 \\
\hline LA850082 & 200.32 & 63.16 & 9.69 & 273.18 & 0.73 & 0.23 & 0.04 \\
\hline ST69132 & 157.41 & 50.41 & 16.46 & 224.28 & 0.70 & 0.22 & 0.07 \\
\hline Mean & 205.84 & 58.40 & 10.17 & 274.41 & 0.75 & 0.21 & 0.04 \\
\hline
\end{tabular}


Table 3. (contined)

\begin{tabular}{lrrrrrrr}
\hline & W5-P1 & W5-P2 & W5-P3 & W5 & W5-P1 & W5-P2 & W5-P3 \\
\cline { 2 - 9 } CB1135 & 152.59 & 46.13 & 8.94 & 207.66 & 0.73 & 0.22 & 0.04 \\
CB219 & 150.21 & 35.63 & 8.65 & 194.48 & 0.77 & 0.18 & 0.04 \\
CB232 & 167.95 & 46.97 & 11.50 & 226.42 & 0.74 & 0.21 & 0.05 \\
CB407 & 242.98 & 66.63 & 10.95 & 320.55 & 0.76 & 0.21 & 0.03 \\
DES119 & 105.19 & 35.43 & 6.57 & 147.19 & 0.71 & 0.24 & 0.04 \\
DPL51 & 239.47 & 73.15 & 16.97 & 329.59 & 0.73 & 0.22 & 0.05 \\
DPL5415 & 227.38 & 62.24 & 9.24 & 298.87 & 0.76 & 0.21 & 0.03 \\
DPL5690 & 315.29 & 88.18 & 14.16 & 417.64 & 0.75 & 0.21 & 0.03 \\
DPL90 & 288.27 & 96.94 & 19.00 & 404.21 & 0.71 & 0.24 & 0.05 \\
LA850082 & 214.00 & 40.76 & 8.34 & 263.09 & 0.81 & 0.15 & 0.03 \\
ST69132 & 94.68 & 28.77 & 11.89 & 135.34 & 0.70 & 0.21 & 0.09 \\
Mean & 199.82 & 56.44 & 11.47 & 267.73 & 0.74 & 0.21 & 0.04 \\
\hline
\end{tabular}

†: Averaged lint yield/ha over two years;

$\Delta:$ Wi-Pj refers to week i and position $\mathrm{j}$;

s: W1, W23, W4, and W5 refer to Averaged lint yield/ha over two years in for week 1, 2 and 3, 4 , and 5 (and above);

F: Proportion to total lint yield by position within a specific time period, for example:

W1-P1 refers to the proportion value of position 1 to total boll number in the first week. 
Table 4. Variance components for boll number by week and position.

\begin{tabular}{|c|c|c|c|c|}
\hline & $\mathrm{W} 1-\mathrm{P} 1^{+}$ & W1-P2 & W1-P3 & $\mathrm{W} 1^{\neq}$ \\
\hline$V_{\mathrm{G}}$ & $43.06 \pm 11.94$ & $1.09 \pm 0.28$ & -- & $55.28 \pm 15.46$ \\
\hline$V_{\mathrm{GE}}$ & $34.06 \pm 10.07$ & $1.01 \pm 0.28$ & -- & $35.98 \pm 11.30$ \\
\hline$V_{\mathrm{e}}$ & $126.73 \pm 48.43$ & $2.92 \pm 0.88$ & -- & $135.54 \pm 52.10$ \\
\hline \multirow[t]{2}{*}{$V_{\mathrm{P}}$} & $203.86 \pm 50.06$ & $5.02 \pm 0.91$ & -- & $226.80 \pm 51.58$ \\
\hline & W23-P1 & W23-P2 & W23-P3 & W23 \\
\hline$V_{\mathrm{G}}$ & $0.00 \pm 0.00$ & $20.13 \pm 4.66$ & $1.11 \pm 0.39$ & $44.42 \pm 15.06$ \\
\hline$V_{\mathrm{GE}}$ & $77.50 \pm 25.39$ & $0.00 \pm 0.00$ & $1.54 \pm 0.47$ & $83.29 \pm 30.86$ \\
\hline$V_{\mathrm{e}}$ & $188.64 \pm 30.21$ & $47.53 \pm 7.51$ & $6.36 \pm 1.84$ & $251.53 \pm 55.07$ \\
\hline \multirow[t]{2}{*}{$V_{\mathrm{P}}$} & $266.14 \pm 39.33$ & $67.66 \pm 7.64$ & $9.02 \pm 1.70$ & $379.23 \pm 56.33$ \\
\hline & W4-P1 & W4-P2 & W4-P3 & W4 \\
\hline$V_{\mathrm{G}}$ & $12.45 \pm 4.29$ & $3.59 \pm 0.97$ & $0.27 \pm 0.11$ & $26.81 \pm 6.76$ \\
\hline$V_{\mathrm{GE}}$ & $19.71 \pm 5.61$ & $0.00 \pm 0.00$ & $0.00 \pm 0.00$ & $25.74 \pm 7.06$ \\
\hline$V_{\mathrm{e}}$ & $36.29 \pm 7.44$ & $14.96 \pm 2.62$ & $6.46 \pm 3.02$ & $69.73 \pm 8.16$ \\
\hline \multirow[t]{2}{*}{$\underline{V_{\mathrm{P}}}$} & $68.45 \pm 9.34$ & $18.56 \pm 2.64$ & $6.73 \pm 3.01$ & $122.29 \pm 8.49$ \\
\hline & W5-P1 & W5-P2 & W5-P3 & W5 \\
\hline$V_{\mathrm{G}}$ & $140.24 \pm 26.65$ & $12.96 \pm 3.93$ & $0.73 \pm 0.25$ & $281.14 \pm 53.68$ \\
\hline$V_{\mathrm{GE}}$ & $28.38 \pm 8.01$ & $21.28 \pm 4.73$ & $1.21 \pm 0.27$ & $0.00 \pm 0.00$ \\
\hline$V_{\mathrm{e}}$ & $180.35 \pm 48.93$ & $53.91 \pm 18.65$ & $8.45 \pm 2.48$ & $421.50 \pm 88.30$ \\
\hline$V_{\mathrm{P}}$ & $348.98 \pm 43.25$ & $88.15 \pm 17.93$ & $10.38 \pm 2.42$ & $702.64 \pm 92.13$ \\
\hline
\end{tabular}

7: Wi-Pj refers to week i and position j, for example, W4-P1 refers to first position in week 4;

f: W1, W23, W4, and W5 refer as week 1, 2 and 3, 4, and 5, respectively. 
Table 5. Variance components for lint yield by week and position.

\begin{tabular}{|c|c|c|c|c|}
\hline & W1-P1 ${ }^{\dagger}$ & W1-P2 & W1-P3 & $\mathrm{W} 1^{\neq}$ \\
\hline$V_{\mathrm{G}}$ & $2658 \pm 802$ & $48 \pm 12$ & -- & $3156 \pm 964$ \\
\hline$V_{\mathrm{GE}}$ & $2859 \pm 756$ & $80 \pm 17$ & -- & $3541 \pm 927$ \\
\hline$V_{\mathrm{e}}$ & $10931 \pm 4494$ & $124 \pm 44$ & -- & $11744 \pm 4717$ \\
\hline \multirow[t]{2}{*}{$V_{\mathrm{P}}$} & $16449 \pm 4145$ & $251 \pm 39$ & -- & $18440 \pm 4256$ \\
\hline & W23-P1 & W23-P2 & W23-P3 & W23 \\
\hline$V_{\mathrm{G}}$ & $1411 \pm 468$ & $793 \pm 199$ & $32 \pm 14$ & $2657 \pm 1065$ \\
\hline$V_{\mathrm{GE}}$ & $2777 \pm 1004$ & $495 \pm 109$ & $10 \pm 3$ & $3664 \pm 1174$ \\
\hline$V_{\mathrm{e}}$ & $13899 \pm 2479$ & $2519 \pm 717$ & $132 \pm 30$ & $18637 \pm 3608$ \\
\hline \multirow[t]{2}{*}{$V_{\mathrm{P}}$} & $18087 \pm 2926$ & $3808 \pm 738$ & $174 \pm 38$ & $24958 \pm 3706$ \\
\hline & W4-P1 & W4-P2 & W4-P3 & W4 \\
\hline$V_{\mathrm{G}}$ & $839 \pm 204$ & $158 \pm 55$ & $0 \pm 0$ & $1588 \pm 339$ \\
\hline$V_{\mathrm{GE}}$ & $546 \pm 117$ & $0 \pm 0$ & $0 \pm 0$ & $685 \pm 215$ \\
\hline$V_{\mathrm{e}}$ & $1426 \pm 281$ & $544 \pm 87$ & $116 \pm 41$ & $2312 \pm 214$ \\
\hline \multirow[t]{2}{*}{$V_{\mathrm{P}}$} & $2811 \pm 323$ & $702 \pm 104$ & $116 \pm 41$ & $4585 \pm 314$ \\
\hline & W5-P1 & W4-P2 & W5-P3 & W5 \\
\hline$V_{\mathrm{G}}$ & $5126 \pm 923$ & $370 \pm 115$ & $6 \pm 2$ & $9214 \pm 1763$ \\
\hline$V_{\mathrm{GE}}$ & $755 \pm 234$ & $565 \pm 139$ & $22 \pm 6$ & $1362 \pm 348$ \\
\hline$V_{\mathrm{e}}$ & $5163 \pm 1442$ & $1281 \pm 440$ & $141 \pm 36$ & $11343 \pm 2903$ \\
\hline$V_{\mathrm{P}}$ & $11044 \pm 1082$ & $2217 \pm 405$ & $169 \pm 35$ & $21919 \pm 2618$ \\
\hline
\end{tabular}

†: Wi-Pj refers to week $\mathrm{i}$ and position $\mathrm{j}$, for example, W4-P1 refers to first position in week 4;

f: W1, W23, W4, and W5 refer as week 1, 2 and 3, 4, and 5, respectively. 